Review article

\title{
Memory, mood and emotion
}

\author{
Giovanni Kuckartz Pergher* \\ Rodrigo Grassi-Oliveira** \\ Luciana Moreira De Ávila*** \\ Lilian Milnitsky Stein****
}

The present study was performed by the Cognitive Processes Research Group, Graduate Program in Psychology, Pontifícia Universidade Católica do Rio Grande do Sul (PUCRS), Porto Alegre, RS, Brazil, and received a support from CNPq and CAPES.

* Psychologist, MSc. student in Social and Personality Psychology, PUCRS, Porto Alegre, RS, Brazil.

** Psychiatrist, MSc. in Social and Personality Psychology, PhD student in Psychology, PUCRS, Porto Alegre, RS, Brazil.

*** Psychologist, MSc. in Social and Personality Psychology, PUCRS, Porto Alegre, RS, Brazil. **** Psychologist, PhD in Psychology, Professor at the Graduate Program in Psychology, PUCRS, Porto Alegre, RS, Brazil.

Received March 28, 2005. Accepted November 4, 2005. 


\section{INTRODUCTION}

This article aims to point out some of the possible relations between emotional and memory processes, as well as some implications of such interactions. In order to do so, we will start with the definition of relevant terms for the present proposal.

One of the first definitions to be made concerns the terms "emotion”, "mood” and "affection". In the present study, we chose to use a convention that has been used in the literature to make a distinction between those three terms. According to this convention, "emotion” is understood as having a character of reactivity, usually brief, intense and circumscribed, related to a specific environmental event. "Mood", on its turn, is conceived as a more stable and constant characteristic, with a tendency to be more comprehensive and not so linked to specific circumstances. ${ }^{2}$ Finally, "affection" is a term used to refer to the ability of subjectivity and expression of the emotional response; it is the quality and the emotional tonus that follow an idea or mental representation, or, in other words, the emotional component of an idea. ${ }^{3}$

We would like to stress that some of the researches mentioned in this article do not work with those definitions, using the terms "mood", "emotion" and "affection” in different senses. However, we chose to maintain the terms present in the original studies, making critical comments whenever necessary.

The present article will be presented as follows: first, the relations between mood, emotion and memory are discussed, followed by the interactions between emotion and memory. Finally, some implications of the studies on emotion and cognition for applied areas will be discussed, stressing the contributions offered by the practice of psychotherapy and forensic psychology/psychiatry.

The process of searching the references that are part of this article was performed in the following manner: search in MEDLINE and PsycINFO databases for the keywords mood and memory and emotion and memory. Articles and book chapters were included, since our proposal 
was to perform a theoretical review as comprehensive as possible, though not intended to be an exhaustive review.

\section{MOOD AND MEMORY}

In this section, three phenomena will be approached, namely: mood-congruent memory (MCM), mood-dependent memory (MDM) and overgeneralized autobiographical memories (OAM). For each of these phenomena, empirical foundations and explanatory theories are presented.

\section{Mood-congruent memory}

The phenomenon of MCM may be defined as the tendency to codify or recall materials when we are in an affective state consistent with the affective valence of these contents. ${ }^{2}$ This means that, for example, an individual who is in an affective state of joy will codify or recall more easily, and in a greater number, the information that has a positive affection than those that contain depressive material and negative affections. The MCM process can be divided into two moments: (1) mood-congruent judgment and (2) mood-congruent recall.

In the mood-congruent judgment, the information is learned more efficiently due to its affective valence, which is consistent with the individual's mood state at the moment of learning. In two experiments of this type, ${ }^{4,5}$ the participants were first induced to a certain mood state through methods such as hypnosis or by listening to songs with an affective load. This procedure was followed by a learning stage, in which the participants had to perform a task of memorizing lists of sad or happy words. At a later moment, when the individuals were already in an euthymic mood, their memories were tested with regard to the learned materials. In both experiments, there was a significant increase in the recall indices in conditions of mood-congruent judgment (for example, sad words when a sadness mood was induced), in relation to the conditions of mood incongruence (for example, happy words when a sadness mood was induced). 
According to Forgas, ${ }^{6}$ the explanation for results like the ones mentioned above lies in the fact that individuals who are in a particular mood state generate more associations for the information that are congruent with such mood, thus judging them more efficiently. As a corroboration of this hypothesis, there are findings in which happy or sad participants spend more time studying materials that are congruent with their moods and less time with incongruent materials. $^{6,7}$

Mood-congruent recall, in its turn, is characterized by an increase in the recall of materials with the same affective tone as the individual's current mood state. ${ }^{8}$ According to Ellis \& Moore, ${ }^{2}$ the mood-congruent recall is less frequently seen, and its examples are less conclusive when compared to the mood-congruent judgment. The studies presented as evidence of mood-congruent recall may be biased, once the affective valence of the material is almost always associated with the individual's mood state at the moment of the event. In a typical research involving congruent recall, the individual's mood state is assessed or induced. Johnson et al. carried out an experiment demonstrating this type of MCM process. ${ }^{9}$ In that study, the participants - undergraduate students were divided into a clinical sample of depressed and non-depressed. In the experiment, a series of tasks was given to the participants, and, at the end, they were asked to recall the content of the tasks in which they had obtained success or failure. As expected, the tasks in which there was failure were more recalled by depressed participants, and the tasks in which there was success were more recalled by non-depressed individuals. That is, the recall is affected by the person's current mood state, related to the affective valence of the material used. ${ }^{8}$

With regard to MCM, the conclusion is that, in general, its effects take place under the influence of mood states, but its effects seem to be even stronger for the clinical and induced depression. ${ }^{8,10}$ Another factor that seems to have a decisive interference in the MCM is the affective force of the material to be studied. For example, Rinck et al. ${ }^{11}$ observed the classical effects of congruent mood when the words that were studied had a high affective tone, i.e., when they were too emotionally loaded, thus having a high affective valence. However, when the words had a 
medium affective tone, effects of mood incongruence were verified. Thus, it can be concluded that the MCM generally depends on materials highly loaded with emotion.

\section{Mood-dependent memory}

The MDM refers to an increase in the probability the individual has to recall materials that were learned in a particular mood state. ${ }^{2}$ Therefore, if a person hears a certain story while in a sad or depressive mood, such as, for example, at a funeral, this story (independently from its affective tone) will be more easily recalled when the individual is again in a sad mood state.

The MDM is different from the MCM because what is important in the former is the consistency of the mood state in judgment and recall. In the latter, in its turn, the crucial issue is the consistency between the mood at the moment of judgment and/or recall and the affective content of the information to be learned and/or recalled.

The classical study performed by Bower et al. ${ }^{12}$ gives a good example of a typical experiment analyzing MDM. In that research, the participants were asked to study two lists of emotionally neutral words, one list while they were happy and the other one while they were sad. Later, the participants had to recall the highest number of words they could, in any mood state (happy or sad). Thus, the recall mood state would be consistent or inconsistent with the mood state of material judgment. Using this procedure, the authors observed that individuals who were in the same mood state, both in judgment and recall, recalled more words than the individuals who were in different mood states.

The explanations for the MDM are focused on two areas. The first one concerns specific mood states, comprehending methodologies used in its induction and the intensity of mood states experienced by the participants. The second explanation for the phenomenon of MDM, in its turn, is related to the type or nature of the material used in memory testing.

With regard to specific aspects of mood states, the MDM is not significantly affected by the type of mood induction procedure, ${ }^{13}$ although only a few states had been experimentally examined. 
The MDM has a higher probability of occurring when contrasting states (for example, sadness versus happiness) are induced in the studies, preferentially neutral mood states. ${ }^{14}$ As in MCM, the MDM is more evident when mood states are more intense. ${ }^{15}$ Researchers have raised the hypothesis that more intense moods lead to intense associations with the materials and, thus, when the mood state for information recall combines with the state of judgment, the mood state works as an important clue to recall the memory materials. ${ }^{16}$

With regard to the type or nature of the material to be memorized, Ucros ${ }^{14}$ concluded that the MDM is less likely to occur with memory tests performed in a laboratory than with real life events that have more meaning. Corroborating this conclusion is the study by Eich et al., ${ }^{17}$ who asked the participants to first generate autobiographical states in a particular mood state, and then recall these events a few days later. As a result, the authors found that, when in a consistent mood state in the generation and recall, the participants recalled the memories previously generated better.

Most studies cited used artificial laboratory procedures to induce the affective states to investigate the phenomena of MCM and MDM. Nevertheless, such induction manipulations do not lead to lasting changes, characterizing the states obtained more as an emotional reaction to the procedure than a stable mood change. In other words, it is difficult to precisely affirm if the results obtained from momentary changes of the affective state would also be seen when the moods being investigated suffer natural changes, which are characterized by a higher stability. Furthermore, another confounding factor present in studies in which the "mood" is experimentally induced is the fact that the participants may answer to the memory tests influenced by their expectations regarding the researcher's intentions, creating a possible bias in the results obtained.

\section{Overgeneralized autobiographical memories}

Autobiographical (or episodic) memories are recollections that individuals have of themselves and their own lives. In this topic, we will specifically approach one of the characteristics of autobiographical memories of depressed people. Therefore, the studies presented next investigate 
the memory in individuals with pathological and lasting mood changes, which go beyond circumscribed changes produced in a laboratory. Particularly, we will explain the OAM, which refer to a tendency depressed individuals have to recall their own past in a synthetic, generic and unspecific manner. In other words, patients with depression have a great difficulty in recalling specific events that happened along their life history, leaving only cloudy and diffuse recollections about their past. Thus, there is a tendency of overgeneralized mnemonic processing. ${ }^{17}$

The OAM have a series of implications, ranging from the etiology until the maintenance of depressive states. In the present article, we chose to approach three of these implications, namely, (1) deficits in problem solving skills, (2) difficulty to imagine the future and (3) likelihood of suicidal and parasuicidal acts. This division into three OAM implications was made for didactic purposes, once those processes do not occur independently in practice. ${ }^{18}$

The hypothesis that a tendency to recall autobiographical memories in an overgeneralized manner would lead to deficits in problem solving skills was tested by Goddard et al.. ${ }^{19}$ In their experiments, adults diagnosed with major depression and control participants without this diagnosis were evaluated in terms of problem solving skills (measured by the effectiveness of the solutions presented to deal with the proposed social situations) and of recalling specific autobiographical memories. In general, the data obtained indicated that the individuals with a higher tendency to an overgeneralized recall tended to present less effective solutions for the situations proposed during the problem solving task. In other words, their results pointed to a close relation between a deficit in the performance of problem solving tasks and an overgeneralized recall of autobiographical memories, which was corroborated by other studies. ${ }^{20}$

The OAM have another implication for the depressive disorders: the ability to imagine the future. It is based on our memories of past events that we base our expectations about the future. ${ }^{21}$ Therefore, when the past is recalled in a diffuse and unspecific manner, the projections about what is to come will probably be so. 
Empirical data, which corroborate the existence of an association between OAM and difficulties to imagine the future, were presented by Williams et al.. ${ }^{22}$ In their experiments, individuals who attempted suicide (most diagnosed with depression) and control individuals, with no history of depression, were tested as to their skills in recalling specific autobiographical memories and building (i.e., imagining) future scenarios in detail.

As expected, they verified that the group of suicidal patients presented more indices of OAM recall and built more generic future scenarios. Furthermore, there was a major relation between the nonspecificity of recalled memories and imagined scenarios, which suggests that a nonspecific recall of the autobiographical memory limits the ability to imagine the future in detail.

The third OAM implication is a result of the association between the deficits in problem solving skills and the difficulties to imagine the future, which may lead to a major suicide risk.

It is known that people who commit suicidal acts are usually in a situation of great hopelessness, i.e., they have a very negative view of the future, associated with a perceived inability to favorably change it. ${ }^{23}$

Considering that projections about the future are established based on past memories, it is reasonable to suppose that the less precise the memories, the less accurate the expectations about what is to come. ${ }^{22}$ In this sense, the nonspecific memory recall could play a major role in the genesis of key beliefs in suicidal individuals, once it is based on the development of projections that are too cloudy about future circumstances, thus making the establishment of more realistic expectations about the future difficult. Moreover, the OAM promote a perception of the static current situation, once there can be no perspectives of changes and/or imminent improvements when problem solving skills are in deficit.

Several studies investigated the quality of autobiographical memory recall in suicidal individuals. Such researches systematically showed higher indices of overgeneralized recalls by individuals who had previously attempted suicide in relation to controls. ${ }^{24,25}$ 
However, it is worth highlighting that the study of memory in people who suffer from depressive disorders has some limitations. Firstly, most studies do not control the use of medications, which is a factor that may significantly interfere in the results. Secondly, the recurrence of mood episodes may affect the individual's information processing. Therefore, studies that include both participants who are depressed for the first time and participants with recurrent depressive episodes may lead to biased results. Finally, the fact that mood disorders have a tendency to chronicity makes it difficult for researchers to distinguish the roles played by the codification and recall processes, since the individual's mood is generally similar in these two moments.

\section{EMOTION AND MEMORY}

The word "emotion" has been used to refer to an affective state that is present during memory codification and/or recall. ${ }^{12,17}$ From the experimental point of view, it refers to the affective/physiological state that an individual presents during a memory test under stressful conditions. $^{27}$

Researchers interested in studying the effect of emotion on memory should be able to separate "emotion” from other important factors - potentially influential - such as the fact that emotional events are retold several times or are unique and unusual. Due to its physiological nature, measures of physiological parameters during the emotional activation or the use of specific indices for behavioral standards are a good option for such studies. Despite these parameters being respected, the studies produce inconsistent results as to the influence of emotion on memory, namely: (1) facilitation of memory, (2) memory impairment or (3) facilitation of some aspects of memory and impairment of others.

Thus, the theories that try to analyze the connection between memory and emotion should attempt to explain these inconsistencies, besides considering the physiological and behavioral issues 
involved in the information acquisition, codification, consolidation and recall. Due to this reason, the neurobiological variables have to be considered when studying memory and emotion.

The emotion can be experimentally manipulated by presenting, for example, a sequence of slides representing stressing and potentially emotional events, such as an assault or threat, with the aim to simulate a situation of real testimony of these situations. ${ }^{28}$ This type of manipulation tends to jeopardize the performance in recall and recognition tests for the information presented in the slides. Nevertheless, when the emotion is manipulated by presenting words or figures with different emotional loads, the effect on memory tends to be facilitated for these words or figures. ${ }^{29}$

Recognition memory, in its turn, may be influenced by three different manners: (1) emotional words are more easily recognized than nonemotional words; ${ }^{29,30}$ (2) emotional words are recognized in a less discriminated manner than nonemotional words; ${ }^{31}$ (3) nonemotional information, when associated with an emotional context during codification, tends to increment the recall $^{32}$ and recognition performance ${ }^{33}$. In short, it seems to be unquestionable that recall processes are facilitated by emotion. Nonetheless, findings are more conflicting with regard to recognition processes.

The emotion could affect the recall and recognition processes based on the codification processes in three different forms: (1) the emotion could reduce the focus of attention, ${ }^{34}$ which would lead to an increase in memory for emotional contents, with a reduction for more peripheral details; ${ }^{28}(2)$ moderate levels of emotion develop the potential of the codification process and, subsequently, memory performance; however, extreme levels of emotions jeopardize such performance; ${ }^{35}(3)$ in a neurobiological level, the emotional processes are mediated by the amygdala; when it becomes active, its anatomical connections with the cortex may facilitate the processing of any presented stimuli. Additionally, anatomical connections of the amygdala with the hippocampus could directly influence the semantic memory. Thus, the more active the amygdala at the learning moment, the higher the intensity of the memory stored for those facts that present emotional content. $^{36}$ 
In studies in which words in different colors and with different emotional meanings are shown to some people (Stroop paradigm) who were asked to only report the color of the word, independently of its meaning, the name of the color of emotional words demanded more time to be said with regard to the color of neutral words. ${ }^{37,38}$ When this experiment was applied to individuals with posttraumatic stress disorder (PTSD), they took much more time to name the color of emotional words related to the trauma (considered as negative) than neutral or emotionally positive words. $^{39,40}$ This suggests that maybe the chronic stress plays a different role than the acute stress in the influence of mnemonic processes.

The studies that approach the impact of stressing events on memory may be exemplified by the study performed by Schmidt, ${ }^{41}$ who studied the autobiographical memories of the $9 / 11$ terrorist attack in the USA. This author verified that several people reported detailed memories of the consequences of the events; however, such memories were not consistent (they were not photographic memories), besides presenting a poor memory for peripheral details, even if there was an increase for central details. ${ }^{42}$ These data suggest that the question "does emotion improve or worsen memory?” cannot be answered in an absolute manner - the particularities of the findings described in the literature must be considered. In general, the evidences point to the idea that there is a good memory for the "meaning" of these emotional events. On the other hand, strong emotions seem to change the mnemonic processing, leading to a loss for peripheral details. Therefore, there is no impairment or global facilitation of the traumatic memory, but different types of processing acting simultaneously for central and peripheral details.

In addition, it is interesting to understand the effects of emotion on memory based on a curved, nonlinear relation. ${ }^{43}$ According to this relation, the increase in the stress levels would contribute to an improvement of memory until a certain point. After this point, the harmful effects would be intensified, causing a worsening in memories, possibly related to its fragmentation.

Finally, we may ask ourselves: does emotion have its most powerful effects on recall memory because it affects mainly the codification stages? Would the minor effects on recognition 
memory become more powerful if the studies controlled the idiosyncratic meaning of the material to be memorized by the research participant? These are some intriguing questions that deserve more attention by the researchers.

\section{FINAL CONSIDERATIONS}

There are several implications of the studies that investigate the relations between the human mnemonic functioning and emotional processes. Among the main applied areas, in which such studies have major implications, we may cite psychotherapy and the forensic/legal area. For example, should a psychotherapist "trust” when a depressed patient reports that all his/her life is marked by a series of calamities, with nothing good on it? And if the same patient says that they are both wasting their time, since there is nothing that can be done to improve, what knowledge does the therapist need to have in order to perform an adequate intervention?

On the other hand, let us consider a witness of a violent crime who was traumatized by the event. His/her statement is naturally crucial for the trial. Can the memory of such a witness be fully trusted? If so, which would be the best form to interrogate him/her?

Several studies carried out so far have brought researchers more questions than answers which does not mean that valuable knowledge has not been built. The researches investigating the relations between emotion and memory offered a support for the development of essentially practical strategies, such as: the anamnestic therapy for suicidal patients; ${ }^{44}$ the exposure therapy for traumatized individuals; ${ }^{45,46}$ and the cognitive interview, which aims to obtain more accurate and detailed reports from witnesses. ${ }^{47}$

Methodological advances and conceptual definitions that are more widely accepted by researchers prove to be essential, once the data in the literature - which are often inconsistent - may be due to the lack of consensus between those who study the same phenomenon using different labels, or between those who study distinct phenomena under the same label. Different research 
lines are necessary, since it is the only way to have a more profound understanding of such a complex and multifaceted phenomenon as the relation between memory and emotion. 


\section{REFERENCES}

1. Ekman P. Basic emotions. In: Dalgleish T, Power MJ, eds. Handbook of cognition and emotion. New York: John Wiley \& Sons; 1999. p. 45-60.

2. Ellis HC, Moore BA. Mood and memory. In: Dalgleish T, Power MJ, eds. Handbook of cognition and emotion. New York: John Wiley \& Sons; 1999. p. 191-210.

3. Dalgalarrondo P. Psicopatologia e semiologia dos transtornos mentais. Porto Alegre: Artes Médicas; 2000.

4. Bower GH, Gilligan SG, Monteiro KP. Selectivity of learning caused by affective states. J Exp Psychol Gen. 1981;110:451-73.

5. Mayer JD, Salovey P. Personality moderates the interaction of mood and cognition. In:

Fiedler K, Forgas JP, eds. Affect, cognition and social behavior. Toronto: Hogrefe; 1988. p. 87-99.

6. Forgas JP. Mood and judgment: the affect infusion model (AIM). Psychol Bull. 1995;117:3966.

7. Forgas JP, Bower GH. Mood effects on person perception judgments. J Pers Soc Psychol. 1987;53:53-60.

8. Blaney PH. Affect and memory: a review. Psychol Bull. 1986;99:229-46.

9. Johnson JE, Petzel TP, Hartney LM, Morgan R. Recall of importance ratings of completed and uncompleted tasks as a function of depression. Cognit Ther Res. 1983;7:51-6.

10. Matt GE, Vazquez C, Campbell WK. Mood-congruent recall of affectively toned stimuli: a meta-analytic review. Clin Psychol Rev. 1992;12:227-55.

11. Rink M, Glowala U, Schneider K. Mood-congruent and mood-incongruent learning. Mem Cognit. 1992;20:29-39.

12. Bower GH, Monteiro KP, Gilligan SG. Emotional mood as a context for learning and recall. J Verb Learn Verb Behav. 1978;17:573-85. 
13. Haaga DA. Mood state-dependent retention using identical or non-identical mood inductions at learning and recall. Br J Clin Psychol. 1989;28:75-83.

14. Ucros CG. Mood state-dependent memory: a meta analysis. Cognit Emotion. 1989;3:139-69.

15. Eich E. Searching for mood dependent memory. Psychol Sci. 1995;6:67-75.

16. Bower GH. Mood and memory. Am Psychol. 1981;36:129-48.

17. Eich E, Macaulay D, Ryan L. Mood dependent memory for events in the personal past. J Exp Psychol Gen. 1994;123:201-15.

18. Pergher GK, Stein LM, Wainer R. Estudos sobre a memória na depressão: achados e implicações para a terapia cognitiva. Rev Psiq Clin. 2004;31:82-90.

19. Goddard L, Dritschel B, Burton A. Role of autobiographical memory in social problem solving and depression. J Abnorm Psychol. 1996;105:609-16.

20. Pollock LR, Williams JM. Problem solving and suicidal behavior. Suicide Life Threat Behav. 1998;28:375-87.

21. Tulving E, Lepage M. Where in the brain is the awareness of one’s past? In: Schacter DL, Scarry E, eds. Memory, brain and belief. Cambridge: Harvard University Press; 2000. p. 20828.

22. Williams JM, Ellis NC, Tyers C, Healy H, Rose G, Macleod AK. The specificity of autobiographical memory and imageability of the future. Mem Cognit. 1996;24:116-25.

23. Beck AT, Rush AJ, Shaw BF, Emery G. Terapia cognitiva da depressão. Porto Alegre: Artes Médicas; 1997.

24. Pollock LR, Williams JM. Effective problem solving in suicide attempters depends on specific autobiographical recall. Suicide Life Threat Behav. 2001;31:386-96.

25. Williams JMG, Broadbent K. Autobiographical memory in suicide attempters. J Abnorm Psychol. 1986;95:144-9.

26. Williams JMG, Watts FN, Macleod C, Mathews A. Cognitive psychology and the emotional disorders. 2nd ed. Chichester: John Wiley \& Sons; 1997. 
27. Baddeley AD. Selective attention and performance in dangerous environments. Br J Psychol. 1972;63:537-46.

28. Christianson SA, Loftus EF. Memory for traumatic events. Appl Cognit Psychol. 1987;1:22539.

29. Doerksen S, Shimamura AP. Source memory enhancement for emotional words. Emotion. 2001;1:5-11.

30. Pesta BJ, Murphy MD, Sanders RE. Are emotionally charged lures immune to false memory? J Exp Psychol Learn Mem Cogn. 2001;27:328-38.

31. Maratos EJ, Allan K, Rugg MD. Recognition memory for emotionally negative and neutral words: an ERP study. Neuropsychologia. 2000;38:1452-65.

32. Kleinsmith LJ, Kaplan S. Paired-associate learning as a function of arousal and interpolated interval. J Exp Psychol. 1963;65:190-3.

33. Maratos EJ, Rugg MD. Electrophysiological correlates of the retrieval of emotional and nonemotional context. J Cognit Neurosci. 2001;13:877-91.

34. Easterbrook J. The effect of emotion on cue utilization and the organization of behavior. Psychol Rev. 1959;66:183-201.

35. Yerkes RM, Dodson JD. The relation of strength of stimulus to rapidity of habit-formation. $\mathrm{J}$ Comp Neur Psychol. 1988;18:459-82.

36. McIntyre CK, Power AE, Roozendaal B, McGaugh JL. Role of the basolateral amigdala in memory consolidation. Ann N Y Acad Sci. 2003;985:273-93.

37. Mathews A, MacLeod C. Selective processing of threat cues in anxiety states. Behav Res Ther. 1985;23:563-9.

38. Watts FN, Trezise L, Sharrock R. Processing of phobic stimuli. Br J Clin Psychol. 1986;25:253-9. 
39. McNally RJ, Clancy SA, Schacter DL, Pitman RK. Cognitive processing of trauma cues in adults reporting repressed, recovered, or continuous memories of childhood sexual abuse. $\mathrm{J}$ Abnorm Psychol. 2000;109:355-9.

40. Metzger LJ, Orr SP, Lasko NB, McNally RJ, Pitman RK. Seeking the source of emotional Stroop interference effects in PTSD: a study of P3s to traumatic words. Integr Physiol Behav Sci. 1997;32:43-51.

41. Schmidt SR. Autobiographical memories for the September 11th attacks: reconstructive errors and emotional impairment of memory. Mem Cognit. 2004;32:443-54.

42. Christianson SA, Loftus EF, Hoffman H, Loftus GR. Eye fixations and memory for emotional events. J Exp Psychol Learn Mem Cogn. 1991;17:693-701.

43. Brewin CR. Memory processes in post-traumatic stress disorder. Int Rev Psychiatry. 1991;13:159-63.

44. Williams JMG. Autobiographical memory and emotional disorders. In: Christianson SA, ed. The handbook of emotion and memory: research and theory. Hillsdale: Lawrence Erlbaum Associates; 1992. p. 451-77.

45. Leskin GA, Kaloupek DG, Keane TM. Treatment for traumatic memories: review and recommendations. Clin Psychol Rev. 1998;18:983-1001.

46. Harvey AG, Bryant RA, Tarrier N. Cognitive behaviour therapy for posttraumatic stress disorder. Clin Psychol Rev. 2003;23:501-22.

47. Fisher RP, Geiselman RE. Memory - enhancing techniques for investigative interview: the cognitive interview. Illinois: Charles C. Thomas Publisher; 1992.

\section{ABSTRACT}

The number of studies that aim to understand the interactions between the cognitive and affective processes has been increasing over the past years, mainly due to their several practical implications, particularly for psychotherapy and the forensic field. The objective of this article is to 
present some of the possible interactions between affective processes and memory. Initially, definitions for the terms emotion, mood and affection are presented. Then, the relations between mood, emotion and memory are approached, describing the main phenomena investigated in such areas. For each phenomenon described, empirical foundations and explanatory theories are listed. Finally, the limitations and implications of the studies on relations between mood, emotion and memory are discussed, focusing on the need of a broader consensus among researchers in this area.

Keywords: Memory, stress, mood.

Title: Memory, mood and emotion

\section{Correspondence:}

Lilian Milnitsky Stein

Av. Ipiranga, 6681, prédio 11, sala 933

CEP 90619-900 - Porto Alegre, RS - Brazil

Tel.: +55 (51) 3320.3633

E-mail: lilian@pucrs.br 